International Journal of English Literature and Social Sciences
Vol-6, Issue-2; Mar-Apr, 2021
Journal Home Page Available: https://ijels.com/
Journal DOI: $10.22161 /$ ijels

\title{
Life and Aesthetics: The Artistic World of Kangwei Paintings in Northern Shanxi
}

\author{
Duan Youwen ${ }^{1}$, Ji Lingzhu ${ }^{2}$
}

\author{
${ }^{1}$ Shanxi University, City of Taiyuan, 030006, Shanxi, P. R. China \\ ${ }^{2}$ Taiyuan Normal University, City of Jinzhong, 030619, Shanxi, P.R. China
}

Received: 02 Dec 2020; Received in revised form: 15 Feb 2021; Accepted: 11 Mar 2021; Available online: 08 Apr 2021

(C2021 The Author(s). Published by Infogain Publication. This is an open access article under the CC BY license

(https://creativecommons.org/licenses/by/4.0/).

\begin{abstract}
Kang Wei painting is a form of traditional folk art, and very popular with villagers in the rural areas of Northern Shanxi Province. This comprehensive art form is a product generated in the primitive living environment, and demonstrates the local people's instinctive pursuit and yearning for beauty. The rock paintings appeared during the Paleolithic period can be regarded as its embryonic form. The abundant subject matters and distinctive artistic style of Kang Wei painting have been shaped by the unique natural environments and traditional aesthetic consciousness of the local residents. People in northern Shanxi try to break the silence and sweep away dreariness in the long and cold winter with the passionate and bright-colored Kang Wei paintings. They paint their good wishes for life and interpretations of their inner spiritual world on the walls of their bedrooms to obtain emotional compensation and spiritual consolation. In the course of drastic changes experienced by the traditional Chinese rural society, the material carrier of Kang Wei painting is gradually disappearing, and the local people's aesthetic orientation has taken a new and different turn. As a result, the inheritance crisis of Kangwei paintings occurs since the art form is fading out of the local people's vision, and the folk artists are switching to other professions to earn their living. At present, the situation for rescuing, protecting and inheritance of Kang Wei painting is particularly pressing. Therefore, joint efforts should be made actively by, the government officials in Yuanping country at different levels, the researchers, the painters and the local people to help the traditional art to rejuvenate and adapt to the modern tendency of social development by means of new media.
\end{abstract}

Keywords- Kangwei paintings in Northern Shanxi, tomb murals, artistic spirit, inheritance and transformation.

\section{INTRODUCTION}

Kang Wei painting is a folk painting art form popular in northern Shanxi. Painted on the walls around Kang (炕 in Chinese), heatable sleeping platform made of bricks and adobe, with strong indigenous features and geographical characteristics. As a kind of rural interior decoration with both practical applications and aesthetic functions, Kangwei paintings evolved from various art forms, such as folk paper-cutting, Chinese New Year 
pictures, colored architectural paintings and so on, and they represent local people's vision of life in line with the times. On the whole, it is local people's art, materialized representation and reflection of the villagers' yearning and enthusiasm for life. From the perspective of origin, we can find the ancient roots of the art in the prehistoric rock paintings and murals in the later generations. They are all painted on the walls or cliffs by people according to their realistic sheltering demands, objective environments and subjective emotional expressions. In terms of artistic features and subject matters, the shape and structure of Kang Wei painting are chosen according to the preference and orientation in value and aesthetics of both the painters and home-owners. From the aspect of inheritance and development, the exquisiteness of the painting works mainly relies on the painter's artistry and skills, since art and artisans are inseparable from each other. When there are no artisans, the corresponding folk art will disappear. Whether the inheriting chain of artisans can be continued is crucial for revitalization and innovation of Kang Wei paintings. Only a sufficient number of inheritors can ensure a broader space for rejuvenation of the folk art and maintain its vitality in the long run.

\section{The cultural origin of Kang Wei painting: echoes from the ancient past}

Kang Wei painting, a kind of folk interior decoration painted around the surrounding walls of Kang (炕 in Chinese) can be regarded as family mural. Painted by local artisans, Kang Wei painting art had not received attention from the upper class and literati in the past, although they had existed in the folk for over a thousand years. As a result, there is almost no exact record of Kang Wei painting in the history of Chinese painting. From the point of view of artistic characteristics, Kang Wei paintings belongs to the category of frescoes. However, if judged from the circulation and origin of the murals, the embryonic form of the folk art can be found from the rock paintings in the primitive period. "Just as man began his journey of tool-making and scientific progress, as well as the art of architecture and sculpture, mainly by the use of stone as a basic material carrier, so the art of human painting seems to have begun on stones. In fact, almost all the treasures of primitive paintings found by now have been painted on rock walls."
As early as the ancient times, painting was used as a means to record the social forms and human beings' existing situation of the time, such as hunting, war and nomadic life scenes, revealing the inner spiritual mysteries and aesthetic concepts of the ancestors, and being a true portrayal of early social life. As one of the main settlements of human beings in ancient times, caves are the place where most of the rock paintings exist. "Kang Wei painting was originally for practical purposes, and gradually had the function of beautification. The simple and pure beauty of Kang Wei paintings reflects the naive imagination and good wishes of human beings in childhood." 2 The red cloud-like rock paintings, which was found 1000 meters east of Yingkou Village, Nanwang Township, Dingxiang County, Xinzhou, show that early men had already decorated their environments with paintings. From the three aspects of rock painting and Kang Wei painting - carrier, function and subject matter we can infer that early Rock painting was the beginning of the art of Kang Wei painting. Firstly, both share a common material carrier, the wall (precipice) of an abode or mountain. Secondly, both have the function of decorating the environment and expressing emotions. Finally, the themes presented by the two are also somewhat related, as the rock paintings of the primitive period mainly focus on hunting and funerals, while the Kang Wei paintings mainly reflect images of life, historical figures, operatic allusions, fruits and seasonal vegetables, etc. Both are wall (cliff) decorative arts derived from real life.

No final conclusion has yet been reached on the matter that Rock painting is the source of the art of Kang Wei painting. The definitive archaeological evidence proves that the origin of Kang Wei paintings can be dated back to Song dynasty at the latest in Yuanping County. "When the railway was built in 1985, a tomb was excavated from Ban village, Yuanping town, containing a bedroom-like room, surrounded by painted murals, which also resembled wall surrounds of the rural dwellings." ${ }^{33}$ In addition to Kang, the iconic carrier, there are plain border decorations similar to the present day boundary pattern of Kangwei paintings, fixed space( called 画空 Huakong) for the themed picture: Guo Ju burying Son to save food for his Mother, one of the twenty-four filial piety stories. Based on the examination of these elements and 
their characteristics, the tomb mural was tentatively identified as a form of Kang Wei painting from the Song dynasty (960-1279A.D.). There are similarities between the murals in tombs and temples and Kang Wei paintings in local residents' bedrooms. In terms of the form of the painting, although there is difference in size, the structure of the boundary pattern and Huakong is the same. From the perspective of the subject matter of the paintings, the tomb murals mostly describe lifetime recreations of the tomb host, and the temple murals are dominated by religious figures and stories, also found sometimes in the themes of the Kang Wei paintings. Judging from the purpose of the paintings, the occurrence of tomb and temple murals are all driven by certain kind of religious belief, and the Kang Wei paintings also have overtones of folk belief. People hope to be blessed by some mystical power and pray for a fulfilling life through paintings. In addition, many of the Kang Wei painters have multiple jobs and have experiences of painting in temples. The art of Kang Wei painting epitomizes many artistic techniques, and the lines, colours and themes of traditional Chinese painting have all been applied to the creation of Kang Wei painting by the folk craftsmen.

Kang is the vehicle for the existence of Kang Wei painting, which is mainly popular in Shanxi and other areas north of the Yellow River, and is a unique way of heating in the long and cold winter. Located in the northern part of the Loess Plateau, northern Shanxi has always been a place where ethnic minorities and Han Chinese mingled and intermingled in history, forming unique multi-cultural qualities of ethnic fusion between Han and various nomadic groups. The ecological environment here is characterized by a thick loess-covered plateau dotted sparsely with villages, vast and boundless with a monotonous atmosphere. People here expect bright colors and beautiful scenery of Southern China in winter. The frequent military upheavals and the hardships of life on the frontier forged the unique cultural character of the local dwellers, who were both delicate and soft, nurtured by the farming civilization, and robust and strong, formed in many years of frontier fortress. To adapt to this natural climate, people used Kang to keep warm, which later gave rise to the folk art form of Kang Wei painting. The Kang was a special resting place in the north closely related to people's life, the centre of layout in the house of a family, and an important space for members' activities and communication. " Kang is immovable; where it is built, there it sits; and where it sits, there it is rooted. So we modify it with the quantifiers that describe the mountain and the wilderness, standing like a mountain and stretching out like vast wilderness in northern winter." ${ }^{4}$ In the old days, in the countryside, many tedious affairs were carried out on the Kang in winter. Many times the whole family sat around the warmth of the Kang: the women did their knitting and sewing; the old people told stories of the past; the children clustered together; perhaps the neighbors and friends came over to chat about everyday matters. Whenever they sat cross-legged, Kang made people feel warm and comfortable. It is not only a place for people to rest, but also a small meeting centre. It served many domestic functions and was a platform for family members to spend time together and communicate with their friends, neighbors and relatives. Therefore, the decoration of Kang became a necessity. In the beginning, the beddings stacked in the corners of the Kang often got polluted by the peelings and dust from the walls. For the purpose of protection, people mixed glue and paint together to cover the earthen walls and embellished them with simple lines. Later, as people's living standards and aesthetic tastes improved, the form of Kang Wei painting became more and more elaborate, gradually forming a unique artistic style. The people of northern Shanxi would turn their ideals of life into beautiful Kang Wei paintings with the help of skillful folk craftsmen. Their persistence of pursuit for happiness in the harsh living environment crystallized into the folk art on the bedroom walls.

\section{ARTISTIC SPIRIT: A WORLD OF POETRY AND PAINTINGS ON THE LOESS PLATEAU}

\subsection{Aesthetic value}

"Symbols are the carriers of culture, medium of cultural creation, transmission and inheritance. Each Kang Wei painting is a symbolic text, a smallest unit of Kang Wei culture." 5 The cultural symbol is composed of two sections: boundary pattern and Huakong (画空 in Chinese, 
the space for the major picture). By means of metaphor and symbolic rhetoric, people's good wishes for happy life are transformed into these meaningful cultural symbols. Boundary pattern is the highlight of Kang Wei painting that is made of a number of traditional auspicious patterns painted in gradient colors, changed lines and continuation of some patterns in different combinations. It is the essence of the painting. There is a local saying in Yuanping: "The quality of a set of Kangwei painting is decided by the degree of fineness of the boundary pattern." The abstract and exquisite boundary patterns contain people's good wishes and beautiful dreams for life. For example, the bat pattern signifies blessing and happiness, because “蝠”(the character for bat in Chinese) and “福” (the character for happiness) are homophones in Chinese. Another example in taken form the legendary stories of the Eight Immortals in Taoism. Painters use their magic weapons to represent them, hoping for a safer and easier life under the protection of these weapons.

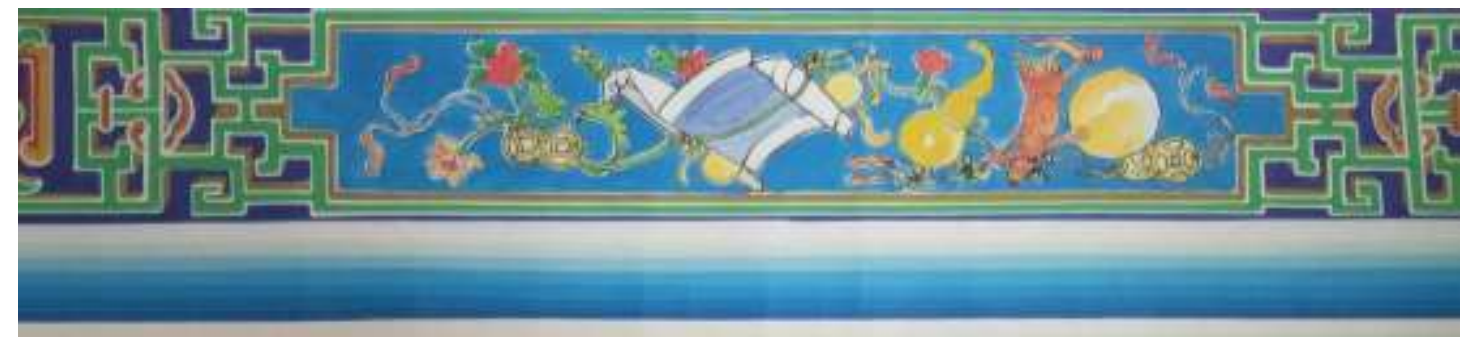

Fig. 1: The Magic weapons of the Eight Taoist Immortals

Taken by Prof.Duan Youwen on Oct.2, 2018 in Yuanping Kangwei Culture and Art Co. ltd.

The masses turn their feelings into the visual images of boundary patterns, which integrate natural forms and abstract shapes. The decorative patterns, usually the combination and variation of colors and lines, create a harmonious visual effect. Beside the boundary patterns, Huakong is another major component of Kang Wei painting. "Huakong is a space (in different shapes) encircled by countless boundary patterns, and the content in it is an independent and complete scene or part of the plot. It is usually in shapes of square, circular, fan-shape, diamond or the irregular etc. Themes of pictures inside Huakongs include complete scenes of flowers, sceneries, still life objects and so on." ${ }^{\circ}$ Through the division and combination of different styles of Huakong, the painters present vivid historical stories, familiar opera excerpts, elegant southern scenery and other themes in the overall layout of Kang Wei painting, making the paintings "narrators" of different stories. Kang Wei paintings in northern Shanxi cover a wide range of thematic areas, but usually closely connected with the local life: figures, landscape and flower-and-bird paintings. Figure paintings are often extracted from historical allusions and classical Chinese operas, depicting important plots and representative roles. The subjects of figure Kang Wei painting include traditional dramas and novels such as Taming Princess Jinzhi, ${ }^{1}$ and The Legend of White Snake, (2) etc; The commonly painted historical stories include Brotherhood Forged in the Peach Garden, (3) Three Visits to the Thatched Cottage, (4) etc; Movie stars popular with the audience in 1980s, such as Ms. Liu Xiaoqing and Ms. Li Xiuming, were also favorite choices during that period. Some landscapes and flower-and-bird works imitated the styles of traditional literati paintings with inscriptions of poetic lines with similar themes. After the founding of People's Republic of China, with the development of times, the well-known modern buildings became popular among local artisans and people. The landscape works are divided into idyllic poetry paintings, such as The Autumn Moon Over the Calm Lake and Spring Birds, and Chinese modern buildings, such as The Great Hall of the People, Nanjing Yangtze River Bridge, etc. The flower- and-bird paintings present typical subjects in traditional ones, such as peony and chrysanthemum, very familiar to the public. The common animal themes of the folk are Chinese pheasants, cats, tigers and others, which symbolizes auspiciousness, longevity, happiness and blessings. "In these colorful Kang 
Wei paintings, the audience can read Chinese history, local customs, social changes and people's daily life, feel the vibrant creative power of the local people, and appreciate the ingenious truthfulness of the folk art."

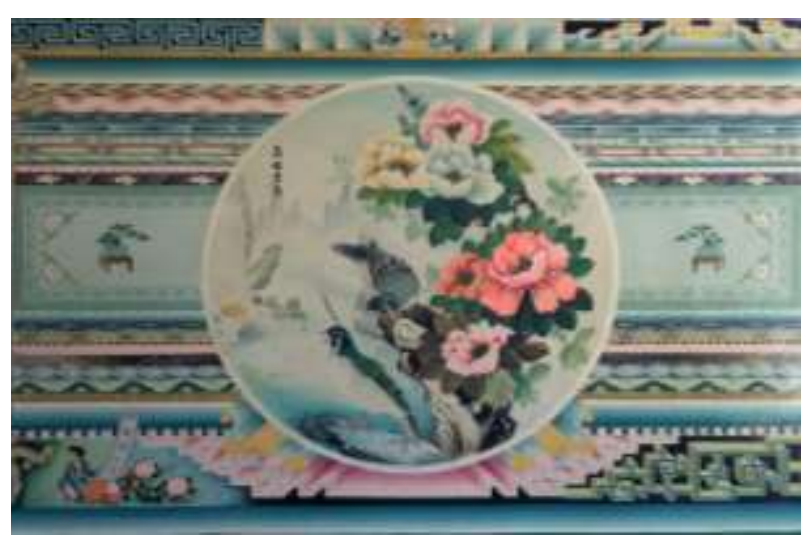

Fig.2: Flower-bird painting

(Painted by Mr. Huang Jiandu and Mr. Wang Liting in 1990)

Courtesy of Mr. Liu Guochen Oct.3, 2018

At the Home of Mr. Huang Jiandu, a local painter in Village Guoyang, Yuanping county

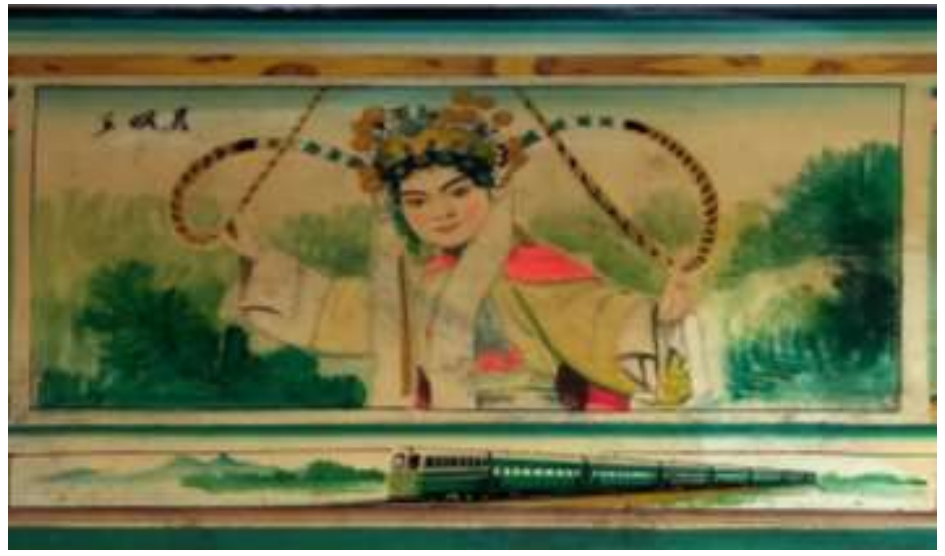

Fig.3: Wang Zhaojun, one of the four well-known beauties in Chinese history

Courtesy of Miss Ji Huizhu Oct.3, 2018

At the home of Li Erlan, Shenshan Temple Village of Yuanping

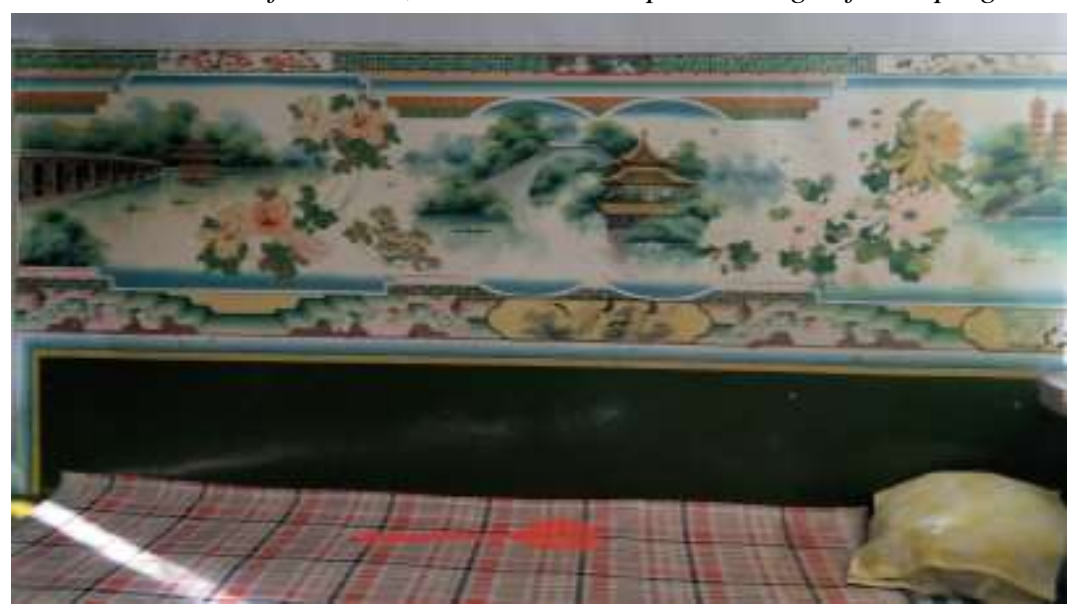

Fig.4: The scenery painting (painted in 1988)

Courtesy of Miss Ji Huizhu, Oct.3, 2018

Taken at the home of Zhao Haichi and Chen Aiping in the Shenshan Temple village, Yuanping County 
As a kind of symbolic text, the romantic paintings are the condensate of people's emotions, aesthetic consciousness and values, bursting with the painters and the house owners' understanding of life and beautiful innermost feelings. Most of the artisans are local farmers who have not received professional training. However, they are able to create moving works to decorate people's houses with their own perception and ardent affections with life. "The self confirmation of human beings is an object- oriented activity, while the most fundamental way is practice." 8 The people's abstraction of realistic life practice, emotional experiences and mental existence are dynamically and sensitively reflected on the Kang Wei paintings, leading to the creation of beautiful art works. Instinctive spiritual communication and emotional accumulation result from the subjective cognitive activities of the people and the object, Kang Wei paintings. Through everyday sensory contact with boundary patterns and the pictures in Huakongs, the recognition of beauty arises from the hearts of the masses after further improvement in their spiritual world at the consciousness level.

\subsection{Functions}

The rich variety of boundary designs and pictures in Huakongs are the abstract representations of life longings and good visions of the people in northern Shanxi, which have profound cultural and symbolic meanings. The ingenious composition of the painting and careful depicting in the limited space on the bedroom wall shows viewers the people's most essential thoughts and emotions. Their spiritual world gets comforted and compensated from the moral enlightenment and psychological satisfaction gained in the course of appreciation. One of the basic functions of Kang Wei painting is to help people to express their feelings. In northern Shanxi, it is vast, gray and all plants withered in the long winter. People are confined indoors by the geographical location and natural conditions , and the warm sleeping platform at night is also the gathering place for family members' and friends' meeting at daytime and evenings. So many Kang Wei paintings are bright in color and gorgeous in patterns with sceneries found in the south China, forming an obvious contrast with the local winter outdoor environment. In this way people hope to get spiritual compensation to soothe their tiring feelings from the fatigue of managing to survive, and to raise their enthusiasm for future.

Kang Wei painting is not only the reproduction and creation of beauty, but also the transmission of moral concepts and value recognition. In daily life, from repeatedly looking at or talking about the pictures, the traditional values can be imperceptibly rooted in the spiritual world of the locals generation after generation. During our investigation in Yuanping, a senior craftsman in his seventies, Mr. Gong Jinshou, narrated one of his painting experiences. In 2017, he painted a set of Kang Wei painting for a family in Wuyan village themed Tigers Learning Surviving Skills. The house owner chose this theme since he accused his children of neglecting their filial duties, and hoped the painting could teach them a filial piety lesson. Kang Wei painting has been adopted as a tool of education by using morals in the folk or virtues from traditional dramas. "As the themes of Kangwei paintings change with the times, constantly replaced by new elements from contemporary life, the subject matter is no longer merely the traditional, but up-to-date content and more-related to people' actual life . As a result, the modern themes of the paintings will play a role in improving the local people's cultural quality, and cultivate their awareness of paying attention to the important national events and social developments." themes expressed by Kang Wei paintings after 1949 are generally the miniature of the times, reflecting the aesthetic interests of people in their specific space, and presenting the cultural awareness and ideology of a particular period of time. Before the founding of People's Republic of China (1949 A.D.), most of subjects of the art were traditional fairy tales, filial piety stories, drama plots and so on. During the early stage of People's Republic of China(from 1950s-mid 1960s), they were endowed with political power and became a publicity billboard that highlighted the themes of those years: new achievements in economic construction and other national appeals.

Many artisans painted Kang Wei paintings to reflect the fruits of social, economic and cultural construction in new China, such as Nanjing Yangtze River Bridge, and The Great Hall of the People in Beijing . During the Cultural Revolution period (1966-1976), due to the high-pressure policies, traditional themes of filial piety and legendary stories were banned. There had been new 
changes in the subjects of the paintings: modern transportation vehicles became the favorites of the painters and the house owners, such as trains, planes and rockets, etc. After the economic reform and opening to the outside world (1978-), people were more open-minded, their favorite movie stars once became the commonly chosen themes. Kang Wei paintings performed the roles of decorating the bedrooms as well as aesthetic, moral and political education. These special paintings permanently freeze the happenings of different periods of time in the limited space in the bedrooms of rural houses, and form a platform for the public to communicate with the outside world. The invisible consciousness orientation generated from the art form shapes the viewers' spiritual world.

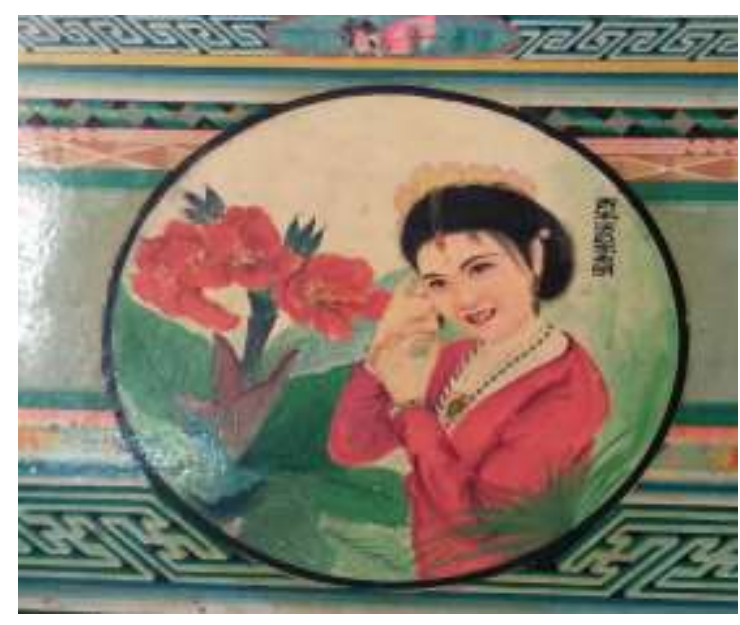

Fig.5: Li Xiuming, a film star in1980s (painted by Mr. Xing Cunshou in 1981)

Courtesy of Miss Jia Kailu, Oct.3, 2018,at the home of Li Shuhua in Shenshan Temple Village, Yuanping

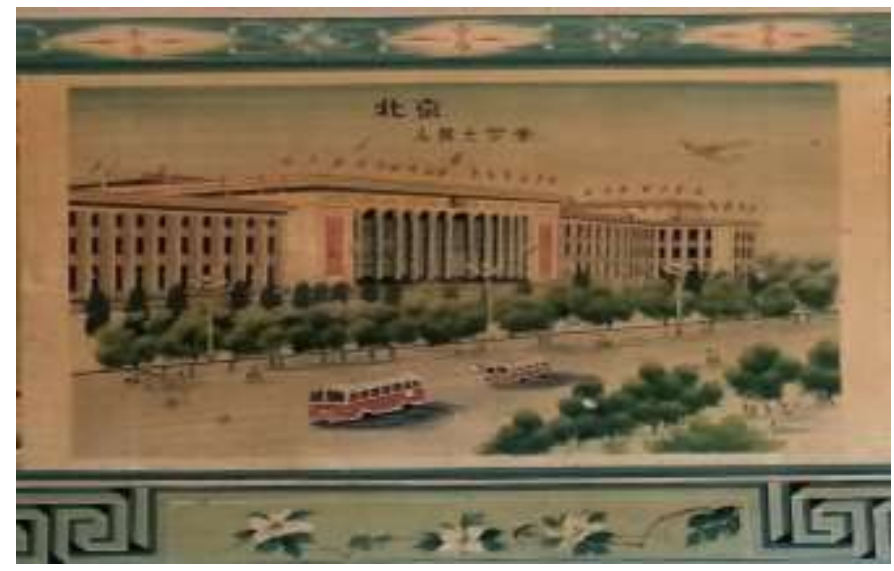

Fig.6: The People's Geat Hall in Beijing (painted by Mr. Huang Jiandu in 1978)

Courtesy of Miss Jia Kailu, Oct,3,2018 in the home of Kang Meisuo in Chunyang Shangshisi Village of Yuanping County

\subsection{Regional features}

Since both the audience and painters of Kang Wei paintings come from the laboring class at the bottom of the social ladder, their living experiences and insights on life determine that the original and simple artistic features of the folk art remain unchanged. In the specific natural and social environment, the painters transform the integration of the objective world and their perception to the paintings, which imitates and dramatizes their local living reality. Each pattern depicts people's yearning for happiness and presents their pursuits for a better life. The themes of the largest proportion of Kang Wei paintings we collected are Chinese traditional dramas, flowers, birds and landscapes. The next largest proportion is historical stories 
and characters. These paintings visualize the most popular and well- known folk tales to meet people's visual and psychological needs. In Shenshan Temple Village, Yuanping country, there is a Kang Wei painting themed $\mathrm{Su}$ Xiaomei ( a well-known poetess in Song Dynasty), very different from the rest in our collection. After the new house was completed in 1987, the hostess, Ms. Chen Aiping, invited a craftsman, Mr. Hu Nian, to draw this painting on the walls in her bedroom at a cost of 170 yuan. She read this traditional folk story of the famous poetess, $\mathrm{Su}$ Xiaomei, in a pictorial magazine and liked her very much. In order to better express rural women's wisdom and capability, the painter creatively exchanged the positions of Su Xiaomei and her husband, Qin Guan, to highlight the female image in the painting.

In the role assignment of traditional rural families in northern Shanxi, women are mainly responsible for the daily routine, and their living space is a detached rural courtyard encircled by walls with some distance to the neighbors . Therefore, for interior decoration, the content, colors and style of Kang Wei painting are often determined by the hostesses' preferences. Women usually prefer flowers-and-birds, landscape, and delicate boundary patterns. They also like bright and rich colors. To cater to the taste of the hostesses, the artistic style of Kang Wei painting presents the tendency of female preferences. Rooted in the profound folk culture soil, Kangwei painting is an indispensable component of the local folk customs, since the contents and forms are strongly influenced and constrained by the folk psychology and reflect the traditional etiquettes in daily life or folk festivals. For example, after people finish building a new house, as a necessary procedure of room decoration, the house owner asks the artisans to draw Kang Wei painting according to his financial affordability. During our investigation in Shangshi Temple Village in Guoyang Town, Yuanping Country, we interviewed the folk artists , Mr. Wang Liting and his master Mr. Huang Jiandu. After Mr. Huang Jiandu's new house was built in 1990, they spent more than 20 days to draw a set of Kang Wei paintings, created the representative work from successful cooperation between a master and his apprentice. The artisans transform people's plain wishes into artistic creations, the visual images in the bedrooms. The basic Chinese values of truth, goodness and beauty embedded in the vivid pictures are attached to the walls, then the unconscious communication between Kang Wei paintings and the audience will bring emotional resonance.

\section{THE INHERITANCE AND TRANSFORMATION OF KANG WEI PAINTINGS}

Created by the people and handed down from generation to generation, Kang Wei painting is a distinctive folk culture in northern Shanxi, recording and carrying people's local memories and emotions. With the wave of urbanization, the traditional vernacular society has been fractured, and the accompanying vernacular culture has been strongly impacted. Kang Wei painting is essentially an art depending on its carrier, Kang, which is the material basis and cultural symbol for the existence of Kang Wei painting. The disappearance of Kang leads to the decline of Kang Wei painting, whose inheritance and development encountered unprecedented difficulties, because more and more villagers replace Kang with bed and using small domestic boilers for heating as well as cooking.

"As the protagonists of the cultural heritage of Kang Wei painting, the folk Kang Wei painters have been active among the rural residents for thousands of years. They have been enriching the cultural lives of the people with their deft hands and passing on the ancient and plain folk art, being a 'living fossil' of folk culture." 9

In painting, Kang Wei painting craftsmen have developed a systematic process. The first step is the process of wall smoothing: mixing the paste and water glue together with the sieved loam to smooth the wall, then sandpapering and painting it white with lithopone powder. The second step is the painting. Depending on the length of the wall, the craftsmen punch the lines, arrange the painting Huakong (the space for major picture) and make a base draft with pencils. The boundary patterns are usually completed first, divided into different layers according to the depth of the color, from lighter to darker. The method handed down from generations is to draw the base on the paper first with soft lead stick or burnt wicker, and then make rubbings. The third step is to brush the selected area on the wall with alum water and then cover 
it with varnish. The painters usually brush the wall 5 or 6 times with the mixture of alum and water until the wall color remains unchanged when brushed again. This is the secret of success. The last step is to cover it with varnish or tung oil at least twice. In the new century, due to the shift in the aesthetic tastes of the public, the villagers' demand for the painting is shrinking, making it difficult for the art to be inherited. Many artisans helplessly choose to change their profession to earn a living. making it difficult for the art of Kang Wei painting to continue as in the past. Taking Yuanping County as an example, there are three main situations faced by Kang Wei painters. In the first case, some old craftsmen passed away and there is no one to inherit their skills. In the second case, many craftsmen chose to take up other occupations as the income from painting the bedroom walls could not sustain their livelihoods. In the third case, many Kang Wei artists have innovated their Kangwai paintings styles to adapt to modern developments, gradually shifting to the emerging interior decoration of the living room.

Kang Wei paintings are cultural symbols created by the people in their social practice, especially the Kang Wei artists. On the one hand, they make the existing symbols a permanent memory by passing on, imitating and accumulating. On the other hand, the artisans create new works with their own artistic imagination. Mr. Gong Jinshou, an experienced Yuanping Kang Wei painter, inherited the painting skills from his father, Mr. Gong Xiangzhong, whose Kang Wei painting in the temple of Lord Guan in Shahe Town, Fanshi County, as well as a sample of the Romance of the Three Kingdoms were both recognized as masterpieces in Yuanping area. The traditional art of Kang Wei painting is perpetuated and regenerated through bloodlines. The valuable experiences he learned from his father has laid the foundations of Mr.Gong Jinshou's fine Kang Wei painting workmanship and has become an important source of inspiration for his career.

"Indeed, when we put our whole being into the practical activity of creating an object, we will see the light of our life there." 10 The Kang Wei painters pour their lives into the creation of Kang Wei paintings, struggling to develop another dimension beyond life in their limited lifetime, soothing their distressed hearts in an artistic way and sublimating the value of their individual lives.

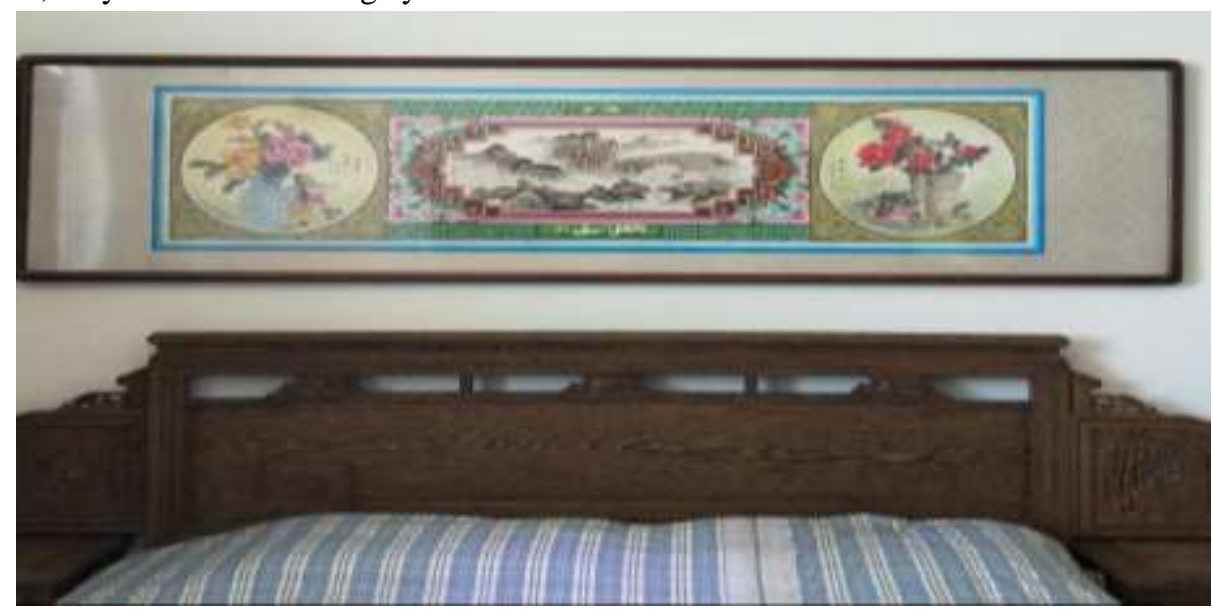

Fig.7: Innovative product by Mr. Li Xiuquan's Company

By Prof. Duan Youwen on Oct.3, 2018 in Yuanping Kangwei Culture and Art Co. ltd.

Nowadays, there are two main groups engaged in the business of Kang Wei painting in Yuanping. One is Yuanping Kang Wei Painting Culture and Art Development Company Limited, established mainly by the manager, Mr. Li Xiuquan, and the other is Yuanping Guoyang Kang Wei Painting Art Research Association, headed by Mr. Wang Liting. These two groups are different in nature. The former is a corporate company of profit-making nature, with a diverse membership. The aim of the company is to bring together old artisans to revive their traditional skills and to paint new Kang Wei paintings that meet the aesthetic preferences of present-day 
consumers. The Manager, Mr. Li Xiuquan, hopes to forge the company into an organization for public benefits as well as profit-making entity, integrating training, reception of tourists, learning and marketing. The company aims at opening a wider market co-supported by the government, enterprises and the whole society.

The latter is a spontaneous group of the folk craftsmen. Most of them are traditional Kang Wei painting painters, hoping to exchange their skills and explore some potential ways to move forward, but have not yet developed the expected social influence."The greater a craftsman's reputation, the more business there is for him." Mr. Wang Liting is aware of the reciprocal relationship between the social status of an artisan and the value of his work, so he has been trying to break through the limitations of his old status perception and actively seek for the opportunity to change by participating in exhibitions and communicating with outside professional painters to gain recognition from the outside world. He is a representative of the new generation Kang Wei painting artisans.

Kang Wei painting is in a predicament of being on the verge of disappearing with fast changes in economy, society and people's way of living. Therefore, we must take measures to bring this folk art back to life so that more and more people will know its artistic and educational values. With the rise of multimedia technology and the development of network transmission, the new media platforms are undoubtedly a good means for the development of Kang Wei painting. For example, a cultural documentary can be made to present a comprehensive picture of Kang Wei painting and to tell the story of its history and tortuous development process. It is also important to maintain and stabilize the chain of inheritance of Kang Wei painting. A suitable environment for Kang Wei painters should be provided by the society, and at the same time the local education department may try to include Kang Wei painting in the planning of art education in primary and secondary schools, and university teachers should be encouraged to study its artistic techniques and cultural background and provide professional guidance for the transformation and development of Kang Wei painting. In addition to these external measures, Kang Wei painting also need to innovate itself, either by combining the technique and subject matter with popular family hand-painted wall art or by changing their carrier (the surrounding walls in the bedroom) form to expand their audience in the form of short interior decorative paintings of the living room. In short, in order for Kang Wei painting to have a broader space for survival, more efforts should be actively made to expand the influence and popularity of Kang Wei painting, strengthen the protection of Kang Wei painters, and promote the transformation of Kang Wei painting in the new era.

\section{CONCLUSION}

The Folk Kangwei painting is a form of remaking natural environment by the people in northern Shanxi, reflection of their inner feelings and cognitive activities in the realistic space. This folk art combines people's aesthetic activities and their living practice, with the folk customs and social happenings of different times and regions as its subject matters. The traditional auspicious blessings and information of different periods of time in the pictures help to preserve people's beautiful memories for life for a longer period of time in history. The folk artisans condense their thoughts for beauty and the house owners' pursuits for a better life into colorful and splendid paintings with their exquisite artistic skills. To the local people, it seems that Kang Wei painting is a bunch of blossoming gorgeous flowers in the barren and lonely land of northern Shanxi, symbolizing the eternal enthusiasm of local people for life, their pursuit for beauty and the most beautiful bright color in the living surrounding. However, Kang Wei painting is gradually fading out of people's vision and lost its past glories with the rapid economic and social development of the times and the drastic changes in the course of urbanization. To save the regional art treasure, it is necessary to arouse the cultural awareness of its subjects - the local artisans and the public. Meanwhile, the joint efforts from the government cultural administrators, local elites and personnels from different scientific research fields are indispensable in the rescuing and inheritance process. 


\section{ACKNOWLEDGEMENTS}

1. The research is a phased achievement of the following research projects

1.1 Key Project sponsored by China Social Science Funds: Genealogy of Folk Cultural Resources in Shanxi, Shaanxi and Henan Provinces and the Empirical studies of Its Innovative Development (Grant No.19ZDA185)

Project leader: Prof. Duan Youwen

1.2 Inheritance and Publicity of Shanxi Folk Kangwei Painintgs (No.2019-10,Document of Taiyuan Normal university)

Project leader: Prof. Ji Lingzhu

1.3 Folk cultural resources in interpreting class supported by Taiyuan Normal University (No. JGLX 2041).

Project leader: Prof. Ji Ling Zhu

2. We are deeply indebted to the help of all the interviewees in our field investigations, the post graduate students in Shanxi University who took the pictures (Miss Ji Huizhu,Mr. Liu Guochen and Miss Jia Kailu) and the undergraduate translation students in Taiyuan Normal University who translated the first draft( Miss Song Jiaqi and Miss Liu Shulin).

\section{REFERENCES}

[1] Yi Zhongtian.(2001). Art Anthropology.[M] Shanghai: Shanghai Press of Art and Literature. P.380.

[2] Yan Liangzhen,2012 On Kang Wei Paintings in Northern Shanxi from the Perspective of Folklore[D]. Shanxi University.

[3] Yuanping County Branch of Chinese People's Political consultative Conference. (1999). Selected Materials of Yuanping History and Culture （unpublished）. P.233.

[4] Feng Rui. (2013). Kangwei Painting: the Withering Folk Art.[J]. Journal of Economic Administrators' Academy. (1)

[5] Xie Xiaolan.(2017). Interpretation of the Cultural Symbols in Shanxi Folk Kangwei paintings.[J]. Cultural Transmission,(5)

[6] Chang Xiaojun. (2014). On the Art Form and Educational Function of Yuan Ping Folk Kang Wei Paintings. Decoration. 2014. pp122-124
[7] Yi Zhongtian.(2001). Art Anthropology.[M] Shanghai: Shanghai Press of Art and Literature. P.39.

[8] Chang Xiaojun.(2014) Artistic Characteristics of Yuanping Kang Wei Painting.[M] Taiyuan: Shanxi People's Publishing House. P 30-32.

[9] Wang Bobo.(2017). The Digital Transmission and Existence of Folk Culture---the case of Shanxi Kangwei Paintings[J]. South-east Transmission,(8).

[10] Yi Zhongtian.(2001). Art Anthropology[M]. Shanghai: Shanghai Press of Art and Literature. P.166.

\section{CULTURAL NOTES}

(1) Taming the Princess, A famous Chinese traditional drama based on an anecdote happened in Tang Dynasty

The emperor's daughter, Princess Shengping, married one of the sons of the top general, Guo Ziyi, but she did not respect her parents-in-law, neither did she perform the duties of a daughter- in-law and a virtuous wife. Her husband, Guo Nuan, had been ashamed of her for a long time. After the banquet of his father's birthday party, he beat her up by means of Dutch courage. The princess felt hurt and snitched on her husband to the emperor. The Guos were very frightened and requested the emperor's punishment for the bold doing. However, the emperor solved the problem wisely according the folk customs. The Guos were forgiven and Princess Shengping was taught to learn to be a daughter-in-law and a wife.

(2) The Legend of White Snake, A Chinese drama based on a legendary story

The drama is about the love story between Madam Bai Shuzhen, an immortal white snake who had a lot of magic after practice for a thousand of years, and $\mathrm{Mr}$. Xv Xian, a human doctor.

(3) Brotherhood Forged in the Peach Garden A Chinese drama based on the story of sworn brotherhood of Liu Bei, Guan Yu and Zhang Fei in Romance of the Three Kingdom

(4) Three Visits to the Thatched Cottage Chinese drama based on Romance of the Three Kingdom

During the three-kingdom period, the emperor of 
Shu , Liu Bei, wanted to become the ruler of whole country, and he was thirsty for talents. Some people recommended Zhu Geliang, a talented and far-reaching man, to him. To get Zhu Geliang's support, Liu Bei sincerely went to visit him three times, overcoming many difficulties. Finally Zhu Geliang was moved, and became Liu Bei's prime minister. 